\title{
One-step synthesis of furan-2,5-dicarboxylic acid from furan-2-carboxylic acid using carbon dioxide
}

\author{
Róbert Fischer* and Mária Fišerová \\ Pulp and Paper Research Institute, Lamačská cesta 3, 84104 Bratislava, Slovak Republic \\ E-mail: robofis@centrum.sk
}

\begin{abstract}
A short and effective method for preparation and isolation of furan-2,5-dicarboxylic acid has been developed. Furan-2,5-dicarboxylic acid was prepared directly from furan-2-carboxylic acid in one step under strong basic conditions using carbon dioxide. This method allows to obtain the product with high added value, furan-2,5-dicarboxylic acid, from natural sources such as hemicelluloses containing pentoses.
\end{abstract}

Keywords: Furan-2,5-dicarboxylic acid, furan-2-carboxylic acids, high added value chemicals, hemicelluloses

\section{Introduction}

Interest in renewable sources of energy and chemicals is increasing because of expected worldwide shortages of easy-to-access oil and gas and growing concern regarding accumulation of greenhouse gases in the atmosphere. The concept of an Integrated Forest Products Biorefinery has been developed by a number of investigators. The idea is to convert biomass into bio-energy and chemicals. ${ }^{1}$ Integrated biorefinery is a process for extracting carbohydrates, oils, lignin, and other materials from biomass and converting them into fuels, high added value chemicals and other materials with almost no waste. ${ }^{2}$ Pulp and paper mills that produce multiple products from biomass can be categorized as biorefineries. Approximately $20 \%$ of the dry wood weight are hemicelluloses which are dissolved in the black liquor and are afterwards burned in the chemical recovery systems. Pre-extraction of hemicelluloses prior to kraft pulping and further conversion to high added value chemicals offer an interesting economic opportunity for pulp and paper industry. ${ }^{3}$

Furan-2,5-dicarboxylic acid (1, FDCA, Figure 1) is a very important chemical substance due to its application in polymerization. It compensates the building blocks in the production of polymers which contain an aromatic moiety. It is also valuable in pharmacology. ${ }^{4-6}$ Moreover, 
furan-2,5-dicarboxylic framework is a current versatile building block for the synthesis of interesting organic compounds and biologically active natural products. ${ }^{7,8}$ The production of FDCA 1 is usually based on the conversion of hexoses under strong acid conditions at high temperatures $^{9,10}$ or on various oxidative processes of 2,5-disubstituted furans, mainly 5(hydroxymethyl)furfural and 5-(hydroxymethyl)furoic acid as C6-substances, compounds containing six carbon atoms mostly derived from biomasses. ${ }^{11-13}$ The mostly investigated method in laboratory involves conversion of furan-2-carboxylic acid methyl ester via chloromethylation exchange of chloro-substituent with hydroxyl group - oxidation process ${ }^{7}$ along with earlier works dealing with the synthesis of furan-2,5-dicarboxylic species. ${ }^{14,15}$

The last named procedure represents multistep synthesis providing FDCA $\mathbf{1}$ and its derivatives in low total yield. On the other hand, this allows the possibility to obtain high added value product FDCA 1 from $\mathrm{C}_{5}$-compounds that can be manufactured from hemicelluloses containing mostly various pentoses ${ }^{16}$ using furan-2-carboxylic acid (2) as intermediate (Figure 1). This strategy has been published for the first time by Fu, Y. and co-workers, who reported a new pathway of converting furfural, a bulk biomass-based chemical, into FDCA including catalytic disproportionation of furoate to furan and 2,5-furandicarboxylate catalyzed by zinc chloride. ${ }^{17}$

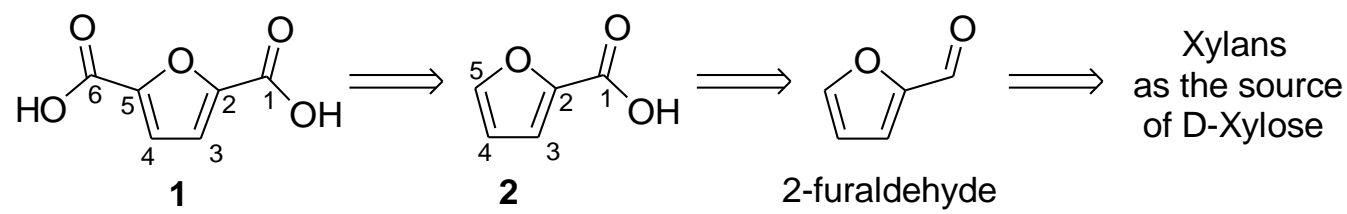

Figure 1. Retrosynthetic analysis of FDCA 1 from $\mathrm{C}_{5}$-compounds.

\section{Results and Discussion}

The addition of the organo-metallic compounds or carbanions generated directly from substituted furans on carbon dioxide is considered to be universal synthetic route for the preparation of a wide range of furan carboxylic acids. ${ }^{18-21}$ Furan ring deprotonisation of furan-2-carboxylic acid derivatives with strong bases such as n-butyllithium or LDA (lithiumdiisopropylamide) has been also published. ${ }^{22,23}$ The first work concerning the generation of dianions directly from furan-2carboxylic acid (2) was published by Knight and Nott. ${ }^{24}$ The authors demonstrated the formation of dianion species by regioselective deprotonisation of acid $\mathbf{2}$ in the position H-5 with LDA and its reactivity with $\mathrm{D}_{2} \mathrm{O}$ and other more or less reactive electrophiles, except $\mathrm{CO}_{2}$. On the other hand, Carpenter and Chadwick investigated the course of lithiation of acid 2, using nbutyllithium and found that the regioselectivity is strongly dependent on the type of the lithium base. ${ }^{25}$ In comparison with LDA, the use of n-butyllithium led to the mixture of 3- and 5deuteriated furan-2-carboxylic acids in a 5:3 ratio. Based on these facts, we decided to focus on a 
shorter and more effective synthesis of FDCA 1 in order to prepare and isolate it in pure form directly from furan-2-carboxylic acid (2) using carbon dioxide (Scheme 1).

The whole practical process till addition of the electrophile was carried out according to literature using $\mathrm{LDA}^{24}$ and n-butyllithium, ${ }^{25}$ respectively. The usual treatment with saturated aqueous $\mathrm{NH}_{4} \mathrm{Cl}$ followed by extraction with ether allowed the solution of lithium furan-2,5dicarboxylate which was subsequently acidified with $2 \mathrm{~N} \mathrm{HCl}$ at $0{ }^{\circ} \mathrm{C}$. A white solid precipitated around $\mathrm{pH} \mathrm{3,} \mathrm{and} \mathrm{was} \mathrm{totally} \mathrm{insoluble} \mathrm{in} \mathrm{organic} \mathrm{solvents} \mathrm{until} \mathrm{strong} \mathrm{acid} \mathrm{was} \mathrm{added.} \mathrm{These}$ facts indicated that we probably isolated some unknown material but most likely not the desired dicarboxylic acid. Fortunately, latter investigations showed that we were able to obtain FDCA 1 in the yield of $73 \%$ after stirring the white precipitate in hydrochloric acid $(2 \mathrm{~N})$ at $80{ }^{\circ} \mathrm{C}$.

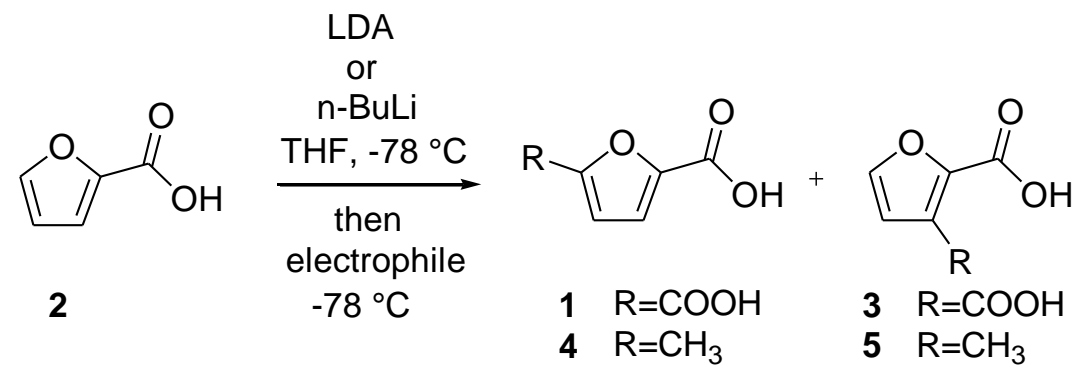

Scheme 1. Preparation of furandicarboxylic acids and methylfurancarboxylic acids.

Table 1. Reactions of furan-2-carboxylic acid 2 with $\mathrm{CO}_{2}$ and methyl iodide

\begin{tabular}{cccccc}
\hline Entry & Type of base & Electrophile & Acid & Ratio & Yield \\
\hline 1 & & & & $\%$ \\
2 & LDA & $\mathrm{CO}_{2}$ & $\mathbf{1}$ & --- & 73 \\
3 & n-BuLi & $\mathrm{CO}_{2}$ & $\mathbf{1 , 3}$ & $50: 50^{\mathrm{a}}$ & --- $^{\mathrm{a}}$ \\
\hline
\end{tabular}

${ }^{\mathrm{a}}$ All ratios were determined from ${ }^{1} \mathrm{H}$ NMR spectra of crude reaction mixtures.

${ }^{\mathrm{b}}$ Yield not given due to difficult isolation of dicarboxylic acids.

${ }^{\mathrm{c}}$ Acids were isolated by column chromatography on silica gel $\left(\mathrm{CH}_{2} \mathrm{Cl}_{2}: \mathrm{CH}_{3} \mathrm{OH}: \mathrm{CH}_{3} \mathrm{COOH}\right.$ 19:1:0.1) as a mixture of both regioisomers.

Though our efforts resulted from the success we wondered if taking n-butyllitium (2.2 equivalents) instead LDA improves the final outcome (Scheme 1). Based on the work of Chadwick and Carpenter ${ }^{25}$ we examined the reaction of furan-2-carboxylic acid (2) with nbutyllithium in THF at $-78{ }^{\circ} \mathrm{C}$ in the same mode like described above. Surprisingly, no dicarboxylic acid precipitated after addition of hydrochloric acid $(2 \mathrm{~N})$ and we extracted the crude product with ethyl acetate after saturation of water layer with $\mathrm{NaCl} .{ }^{1} \mathrm{H} \mathrm{NMR}$ spectra determined the presence of two regioisomers namely furan-2,5-dicarboxylic acid (1) and furan-2,3dicarboxylic acid (3) in ratio 50:50. Furthermore, we observed the inversion of regioselectivity in 
favour of 2,3-regioisomer in comparison with the results reported by Knight and $\mathrm{Nott}^{24}$ by addition of methyl iodide (instead $\mathrm{CO}_{2}$ ) retaining the mixture one hour at $-78{ }^{\circ} \mathrm{C}$. The reaction also provided the mixture of two regioisomers 5-methylfuran-2-carboxylic acid (4) and 3methylfuran-2-carboxylic acid (5) in ratio 35:65 in the yield of 83\%. All obtained results are summarized in Table 1.

Because it is difficult to isolate the carboxylic acids $\mathbf{1}$ and $\mathbf{3}$ we decided to convert them into their methyl esters 6, 7 (Scheme 2). Conventional esterification catalyzed by toluene-4-sulfonic acid failed due to low solubility of initial acids. Furthermore, earlier work provided dimethyl ester 6 in lower yields of $68 \%$ and $59 \%$, respectively. ${ }^{10}$ Therefore, we carried out the reaction in the presence of trimethylsilyl chloride (TMSCl, 2 eq.) in neat methanol under reflux (Scheme 2). This method was already applied in the esterification of furan-2,3-dicarboxylic acid 3 . ${ }^{26}$ Now we have used it in the case of furan-2,5-dicarboxylic acid $\mathbf{1}$ for the first time. All obtained results are summarized in Table 2.<smiles>O=C(O)c1ccoc1C(=O)O</smiles>

1,3

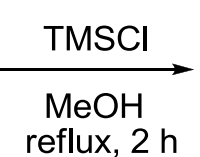

reflux, $2 \mathrm{~h}$

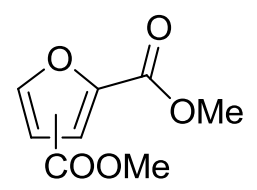

6, 7

Scheme 2. Esterification of furandicarboxylic acids using of TMSCl.

Table 2. Preparation of furandicarboxylic acid dimethyl esters

\begin{tabular}{cccc}
\hline Dicarboxylic acid & Methyl ester & Yield & $\mathrm{mp}$ \\
\cline { 3 - 4 } & & $\%$ & ${ }^{\circ} \mathrm{C}$ \\
\hline $\mathbf{1}$ (purchased from Aldrich) & $\mathbf{6}$ & 82 & $111-112^{\mathrm{e}}$ \\
$\mathbf{1}$ (solid, Table 1, Entry 1) & $\mathbf{6}$ & $55^{\mathrm{c}}$ & $110-111^{\mathrm{e}}$ \\
$\mathbf{1 , 3}$ (crude product, Table 1, Entry 2) & $\mathbf{6 , 7 ^ { \mathrm { b } }}$ & $52^{\mathrm{c}, \mathrm{d}}$ & -- \\
\hline
\end{tabular}

${ }^{\mathrm{a}}$ Ratio 1:3 = 50:50.

${ }^{\mathrm{b}}$ Ratio 6:7 = 50:50.

${ }^{\mathrm{c}}$ Yield calculated after two steps from furan-2-carboxylic acid.

${ }^{\mathrm{d}}$ Esters were isolated as the mixture of both regioisomers.

${ }^{\mathrm{e}} \mathrm{mp} 109-110^{\circ} \mathrm{C} .^{27}$

Unfortunately, we were not able to separate the dimethyl esters 6 and 7 from each other by column chromatography on silica gel. 


\section{Conclusions}

We have successfully prepared furan-2,5-dicarboxylic acid (1, FDCA) from furan-2-carboxylic acid (2) by reaction with LDA in THF at $-78{ }^{\circ} \mathrm{C}$ using carbon dioxide as electrophile. This reaction proceeded regioselectively and provided FDCA 1 in $73 \%$ yield and in satisfactory purity. FDCA 1 was prepared from furan-2-carboxylic acid (2) as representative $\mathrm{C}_{5}$-building block readily available from D-xylose. In addition, we have converted FDCA 1 into furan-2,5dicarboxylic acid dimethyl ester (6) by reaction in neat methanol in the presence of TMSCl with the yield of $82 \%$. Though FDCA is commercially available, the presented method could be an alternative way of its preparation or relative derivatives with high added value from hemicelluloses rich in pentoses. Also, treatment of lithium 5-lithiofuran-2-carboxylate with other reactive electrophiles might be examined in order to prepare interesting building blocks with different carbonyl species in the C-2 and C-5 positions of furan ring. Further studies and experiments are currently in progress.

\section{Experimental Section}

General. All melting points were measured on a Melting Point B-540 apparatus (Büchi, Switzerland) and are uncorrected. NMR spectra were recorded on a Varian VRX-300 spectrometer $\left({ }^{1} \mathrm{H}, 300 \mathrm{MHz}\right.$ Varian, USA) in $\mathrm{CDCl}_{3}$ and DMSO- $d 6$ using tetramethylsilane (TMS) as internal standard. TLC analyses were carried out using TLC Silica gel $60 \mathrm{~F}_{254}$ (aluminium sheets, Merck, Germany) and visualized by UV light or by permanganate solution. Column chromatographies were performed on Büchi system (Pump Manager C-615 and Fraction Collector C-660, Büchi, Switzerland) using Normasil 60 silica gel $(0.040-0.063 \mathrm{~mm})$ (VWR, Germany). All solvents were dried and distilled according to conventional methods. All reagents were purchased from Aldrich (Germany), Acros Organics (Germany), Alfa-Aesar (Germany), Merck (Germany) and Mikrochem Trade (Slovakia) and were used without further purification.

Furan-2,5-dicarboxylic acid (1). A well-dried reaction flask sealed with rubber septum was flushed with argon and charged with diisopropylamine $(1.06 \mathrm{~mL}, 7.5 \mathrm{mmol}$, stored over molecular sieves). n-Butyllithium (4.70 mL, $7.5 \mathrm{mmol}, 1.6 \mathrm{M}$ solution in hexane) was added dropwise at $-10{ }^{\circ} \mathrm{C}$ over $10 \mathrm{~min}$. under argon balloon. The resulting viscous oil stayed at this temperature for $25 \mathrm{~min}$. Afterwards, the reaction flask was cooled to $-78{ }^{\circ} \mathrm{C}$ and in situ prepared LDA was dissolved in dry THF (12 mL). A solution of furan-2-carboxylic acid (2, $400 \mathrm{mg}, 3.57$ $\mathrm{mmol})$ in dry THF $(6 \mathrm{~mL})$ was added dropwise over a period of $20 \mathrm{~min}$. When the solution was added the reaction mixture was stirred for one hour. Subsequently, dry $\mathrm{CO}_{2}$ was bubbled into the solution for $15 \mathrm{~min}$ at $-78{ }^{\circ} \mathrm{C}$ and next $15 \mathrm{~min}$ at $0{ }^{\circ} \mathrm{C}$. Then the resulting slurry was diluted with saturated aq. ammonium chloride $(25 \mathrm{~mL})$. Water was added $(10 \mathrm{~mL})$ and the final liquid phase was extracted with ether $(25 \mathrm{~mL})$. Water layer was separated, cooled with ice-bath and acidified 
with $2 \mathrm{~N} \mathrm{HCl}$ (until $\mathrm{pH} \mathrm{1).} \mathrm{The} \mathrm{precipitated} \mathrm{solid} \mathrm{was} \mathrm{collected} \mathrm{and} \mathrm{stirred} \mathrm{at} 80{ }^{\circ} \mathrm{C}$ in $2 \mathrm{~N} \mathrm{HCl}$ for two hours. The final furan-2,5-dicarboxylic acid (1) was collected by filtration and well dried. Colourless crystals, yield 73\%, $407 \mathrm{mg} ;{ }^{1} \mathrm{H}$ NMR $\left(300 \mathrm{MHz}, \mathrm{DMSO}-\mathrm{d}_{6}\right): \delta_{\mathrm{H}} 7.28(2 \mathrm{H}, \mathrm{s}$ H-3, H-4). The NMR spectra correspond to the literature data. ${ }^{28}$

Furan-2,5-dicarboxylic acid dimethyl ester (6). A reaction flask was charged with furan-2,5dicarboxylic acid (1, $250 \mathrm{mg}, 1.55 \mathrm{mmol}$, 97\%, purchased from Aldrich), equipped with condenser and flushed with argon. Methanol $(0.8 \mathrm{~mL})$ was added, followed by trimethylsilyl chloride $(0.4 \mathrm{~mL}, 3.10 \mathrm{mmol})$. The reaction mixture was stirred for 2 hours under reflux. After removal of the solvent in vacuo, product was isolated by flash column chromatography on silica gel $\left(\mathrm{CH}_{2} \mathrm{Cl}_{2}\right)$. Colourless crystals, yield 82\%, $234 \mathrm{mg}, \mathrm{mp} 111-112{ }^{\circ} \mathrm{C} ;{ }^{1} \mathrm{H}$ NMR $(300 \mathrm{MHz}$, $\left.\mathrm{CDCl}_{3}\right): \delta_{\mathrm{H}} 3.94\left(6 \mathrm{H}, \mathrm{s}, \mathrm{COOCH}_{3}\right), 7.23(2 \mathrm{H}, \mathrm{s}, \mathrm{H}-3, \mathrm{H}-4)$. The NMR spectra correspond to the literature data. $^{27}$

Additional ${ }^{1} \mathrm{H}$ NMR data (300 MHz, DMSO-d 6 ) for furan-2,3-dicarboxylic acid (3), 5methylfuran-2-carboxylic acid (4), 3-methylfuran-2-carboxylic acid (5) and furan-2,3dicarboxylic acid dimethyl ester (7) were obtained from the corresponding mixtures of both regioisomers:

Furan-2,3-dicarboxylic acid (3): $\delta_{\mathrm{H}} 6.87(1 \mathrm{H}, \mathrm{d}, \mathrm{H}-4, J 1.8 \mathrm{~Hz}), 7.90(1 \mathrm{H}, \mathrm{d}, \mathrm{H}-5, J 1.8 \mathrm{~Hz})$. The NMR spectra correspond to the literature data. ${ }^{31}$

5-Methylfuran-2-carboxylic acid (4): $\delta_{\mathrm{H}} 2.33\left(3 \mathrm{H}, \mathrm{s}, \mathrm{CH}_{3}\right), 6.27-6.28(1 \mathrm{H}, \mathrm{m}, \mathrm{H}-4), 7.10(1 \mathrm{H}$, d, H-3, J 3.5 Hz), $12.86(1 \mathrm{H}, \mathrm{bs}, \mathrm{COOH})$. The NMR spectra correspond to the literature data. ${ }^{29}$

3-Methylfuran-2-carboxylic acid (5): $\delta_{\mathrm{H}} 2.27\left(3 \mathrm{H}, \mathrm{s}, \mathrm{CH}_{3}\right), 6.53(1 \mathrm{H}, \mathrm{d}, \mathrm{H}-4, J 1.8 \mathrm{~Hz}), 7.75$ $(1 \mathrm{H}, \mathrm{d}, \mathrm{H}-5, J 1.8 \mathrm{~Hz}), 12,86(1 \mathrm{H}, \mathrm{bs}, \mathrm{COOH})$. The NMR spectra correspond to the literature data. $^{30}$

Furan-2,3-dicarboxylic acid dimethyl ester (7): $\delta_{\mathrm{H}} 3.91\left(3 \mathrm{H}, \mathrm{s}, \mathrm{COOCH}_{3}\right), 3.95(3 \mathrm{H}, \mathrm{s}$, $\left.\mathrm{COOCH}_{3}\right), 6.79(1 \mathrm{H}, \mathrm{d}, \mathrm{H}-4, J 1.8 \mathrm{~Hz}), 7.53(1 \mathrm{H}, \mathrm{d}, \mathrm{H}-5, J 1.8 \mathrm{~Hz})$. The NMR spectra correspond to the literature data. ${ }^{26}$

\section{Acknowledgements}

This work was supported by the Slovak Research and Development Agency under contract No. APVV-0367-10.

\section{References}

1. Mao, H.; Genco, J. M.; Yoon, S.-H.; van Heiningen, A.; Pendse, H. J. Biobased Mater. Bio. 2008, 2, 177.

http://dx.doi.org/10.1166/jbmb.2008.309

2. Carvalheiro, F.; Duarte, L. C.; Gírio, F. M. J. Sci. Ind. Res. 2008, 67, 849. 
3. van Heiningen, A. Pulp and Paper Canada 2006, 107, 38.

4. Gandini, A.; Belgacem, M. N. Prog. Polym. Sci. 1997, 22, 1203. http://dx.doi.org/10.1016/S0079-6700(97)00004-X

5. Lewkowski, J. Arkivoc 2001, (i), 17.

6. Bozell, J. J.; Petersen, G. R. Green Chem. 2010, 12, 539. http://dx.doi.org/10.1039/b922014c

7. Schmuck, C.; Machon, U. Eur. J. Org. Chem. 2006, 4385. http://dx.doi.org/10.1002/ejoc.200600324

8. Yin, B.-L.; Yang, Z.-M.; Hu, T.-S.; Wu, Y.-L. Synthesis 2003, 1995. http://dx.doi.org/10.1055/s-2003-41042

9. Taguchi, Y.; Oishi, A.; Iida, H. Chem. Lett. 2008, 37, 50. DOI: 10.1246/cl.2008.50. http://dx.doi.org/10.1246/cl.2008.50

10. Lewkowski, J. Pol. J. Chem. 2001, 75, 1943.

11. Koopman, F.; Wierckx, N.; de Winde, J. H.; Ruijssenaars, H. J. Bioresour. Technol. 2010, 107, 6291.

http://dx.doi.org/10.1016/j.biortech.2010.03.050

12. Partenheimer, W.; Grushin, V. V. Adv. Synth. Catal. 2001, 343, 102. http://dx.doi.org/10.1002/1615-4169(20010129)343:1<102::AID-ADSC102>3.0.CO;2-Q

13. Brasholz, M.; von Känel, K.; Hornung, C. H.; Saubern, S.; Tsanaktsidis, J. Green Chem. 2011, 13, 1114. http://dx.doi.org/10.1039/c1gc15107j

14. Moldenhauer, O.; Trautmann, G.; Irion, W.; Pfluger, R.; Döser, H.; Mastaglio, D.; Marwitz, H. Liebigs Ann. Chem. 1953, 580, 169. http://dx.doi.org/10.1002/jlac.19535800302

15. Nielek, S.; Lesiak, T. J. Prakt. Chem. 1988, 330, 825. http://dx.doi.org/10.1002/prac.19883300523

16. Feather, M. S.; Harris, D. W.; Nichols, S. B. J. Org. Chem. 1972, 37, 1606. http://dx.doi.org/10.1021/jo00975a032

17. Pan, T.; Deng, J.; Xu, Q.; Zuo, Y.; Guo, Q.-X.; Fu, Y. ChemSusChem. 2013, 6, 47. http://dx.doi.org/10.1002/cssc.201200652

18. Dawson, M. I.; Chan, R.; Hobbs, P. D.; Chao, W.; Schiff, L. J. J. Med. Chem. 1983, 26, 1282. http://dx.doi.org/10.1021/jm00363a013

19. Carpenter, A. J.; Chadwick, D. J. Tetrahedron 1985, 41, 3803. http://dx.doi.org/10.1016/S0040-4020(01)91401-2

20. Magnus, P.; Diorazio, L.; Donohoe, T. J.; Giles, M.; Pye, P.; Tarrant, J.; Thom, S. Tetrahedron 1996, 52, 14147. http://dx.doi.org/10.1016/0040-4020(96)00865-4

21. Takahashi, M.; Kuroda, T.; Ogiku, T.; Ohmizu, H.; Kondo, K.; Iwasaki, T. Heterocycles 1993, 36, 1867. 
http://dx.doi.org/10.3987/COM-93-6394

22. Chadwick, D. J.; McKnight, M. V.; Ngochindo, R. J. Chem. Soc., Perkin Trans. 1 1982, 1343.

http://dx.doi.org/10.1039/p19820001343

23. Carpenter, A. J.; Chadwick, D. J. Tetrahedron Lett. 1985, 26, 5335.

http://dx.doi.org/10.1016/S0040-4039(00)95032-9

24. Knight, D. W.; Nott, A. P. J. Chem. Soc., Perkin Trans. 1 1981, 1125.

http://dx.doi.org/10.1039/p19810001125

25. Carpenter, A. J.; Chadwick, D. J. Tetrahedron Lett. 1985, 26, 1777.

http://dx.doi.org/10.1016/S0040-4039(00)98336-9

26. Klein, M.; Sandner, P.; Frey, R.; Riedl, B.; Christensen, O. WO 2007/118602 (A1), Bayer Healthcare AG.

27. Barton, D. H. R.; Brown, B. D.; Ridley, D. D.; Widdowson, D. A.; Keys, A. J.; Leaver, C. J. J. Chem. Soc., Perkin Trans. 1 1975, 2069.

http://dx.doi.org/10.1039/p19750002069

28. Yoon, D.-W.; Gross, D. E.; Lynch, V. M.; Sessler, J. L.; Hay, B. P.; Lee, C.-H. Angew. Chem. Int. Ed. 2008, 47, 5038.

http://dx.doi.org/10.1002/anie.200801426

29. Collins, M. J.; Hatton, P. M.; Sternhell, S. Aust. J. Chem. 1992, 45, 1119.

http://dx.doi.org/10.1071/CH9921119

30. Cahiez, G.; Chavant, P.-Y.; Metais, E. Tetrahedron Lett. 1992, 33, 5245. http://dx.doi.org/10.1016/j.bbr.2011.03.031

31. Dumas, J. P.; Boyer, S. J.; Dixon, J. A.; Joe, T. K.; Kluender, H. C. E.; Lee, W.; Nagarathnam, D.; Sibley, R. N.; Su, N. US 6689883(B1), 2004, Bayer Pharmaceuticals Corporation. 